\title{
Using Fuzzy PROMETHEE to Select Countries for Developmental Aid
}

\author{
Eric Afful-Dadzie \\ Faculty of Applied Informatics \\ Tomas Bata University in Zlin \\ Zlin, Czech Republic \\ afful@fai.utb.cz \\ Stephen Nabareseh \\ Faculty of Management and Economics \\ Tomas Bata University in Zlin \\ Zlin, Czech Republic \\ nabareseh@fame.utb.cz \\ Zuzana Komínková Oplatková \\ Faculty of Applied Informatics \\ Tomas Bata University in Zlin \\ Zlin, Czech Republic \\ kominkova@fai.utb.cz \\ Peter Klimek \\ Faculty of Management and Economics \\ Tomas Bata University in Zlin \\ Zlin, Czech Republic \\ klimek@fame.utb.cz
}

\section{Abstract}

Wealthy nations continue to demonstrate their unwavering support to improving conditions and the general well-being of poor countries in spite of the recent economic crises. However, as developmental aid relatively shrinks, both Aid donors and recipient countries have shown keen interest in methodologies used in evaluating developmental assistance programs. Evaluation of aid programs is seen as a complex task mainly because of the several non-aid factors that tend to affect overall outcomes. Adding to the complexity are the subjective sets of criteria used in Aid evaluations programs. This paper proposes a two stage framework of fuzzy TOPSIS and sensitivity analysis to demonstrate how aid-recipient countries can be evaluated to deepen transparency, fairness, value for money and sustainability of such aid programs. Using the Organisation for Economic Co-operation and Development (OECD) set of subjective criteria for evaluating aid programs; a numerical example pre-defined by linguistic terms parameterized by triangular fuzzy numbers is provided to evaluate aid programs. Fuzzy PROMETHEE is used in the first stage to evaluate and rank aid-recipients followed by a comparative analysis with Fuzzy VIKOR and Fuzzy TOPSIS to ascertain a accurateness of the method used. A sensitivity analysis is further added that anticipates possible influences from lobbyists and examines the effect of 
that bias in expert ratings on the evaluation process. The result shows a framework that can be employed in evaluating aid effectiveness of recipient-countries.

Keywords-Developmental aid programs; Fuzzy set theory; Organization for Economic Cooperation and Development (OECD); Fuzzy PROMETHEE; Fuzzy VIKOR, Fuzzy TOPAIA, Fuzzy MCDM; Evaluation, Sensitivity Analysis

\section{Introduction}

Despite the incessant call on donor countries for a budget reduction, most organisations still release billions in aid of developing and poor countries. Some of these organisations include the Organization for Economic Cooperation and Development (OECD), UK's Department for International Development (DFID), the United States Agency for International Development (USAID), Canada's Country Indicators for foreign Policy (CIFP), the African Development Bank (AfDB) and the World Bank. A net amount of 132 billion dollars was spent jointly in 2012 and rose to 134 billion in 2013 by wealthy nations to reduce poverty and improve developmental conditions of poor nations [1]. The fall in developmental aid in the past years triggered stringent measures to ensure that donors and recipients alike are thoroughly evaluated to ensure the overall sustainability of developmental aid programs [2,3,4]. This phenomenon, adding to the lack of consensus among researchers about the impact of aid on economic growth $[5,6,7,8]$ and the several instances of changes in aid allocation criteria $[9,10]$ explain the need for robust methodologies to evaluate developmental aid.

Most proposed criteria for appraising development aid are more often subjective apparently because of other non-aid inputs that have the propensity to influence total outcome. Economic recession, food and energy prices, interest rates, trade credits and among others are some non-aid factors capable of affecting the general outcome of an aid evaluation program [2]. The OECD currently adopts five subjective criteria in evaluating their developmental aid programs. These criteria are relevance, effectiveness, efficiency, impact and sustainability used to evaluate developmental aid programs for a particular country. The selection of beneficiaries for aid is sometimes challenging when fuzzy criteria is used. To address this challenge, this paper recommends a fuzzy PROMETHEE framework for evaluating countries involved in developmental aid program performance ranking. The method helps to track the progress of countries whiles ensuring that future aid allocations are based on performance of previous aid programs. The rest of the paper is presented as follows: Modeling uncertainty with fuzzy set theory is briefly explained followed by the definition, review of relevant literature and steps in fuzzy PROMETHEE method. Finally, a numerical example of how fuzzy PROMETHEE could help to evaluate and rank participating countries in developmental assistance programs is presented. 


\section{Modelling Uncertainty with Fuzzy Sets}

Zadeh [11] introduced the fuzzy set theory to tackle issues of uncertainty, imprecision and vagueness in information that are not statistical in nature. The fuzzy sets concept is hinged on a relative graded membership and has been applied extensively in subjective modeling mostly in multi-criteria decision making (MCDM) environments. In fuzzy MCDM, the subjective criteria are represented by linguistic variables which are further expressed with linguistic terms [12]. The following presents the definitions with basic operations of the fuzzy set theory.

\section{A. Fuzzy Set}

Let $X$ be a nonempty set, the universe of discourse $X=\left\{x_{1}, x_{2}, \ldots, x_{n}\right\}$. A fuzzy set $A$ of $X$ is a set of ordered pairs $\left\{\left(x_{1}, f_{A}\left(x_{1}\right)\right),\left(x_{2}, f_{A}\left(x_{2}\right)\right), \ldots,\left(x_{n}, f_{A}\left(x_{n}\right)\right)\right\}$, characterized by a membership function $f_{A}(x)$ that maps each element $x$ in $X$ to a real number in the interval $[0,1]$. The function value $f_{A}(x)$ stands for the membership degree $x$ in $A$. This paper uses the Triangular Fuzzy Number (TFN) defined below for evaluation.

\section{B. Triangular fuzzy number}

In triangular fuzzy number (TFN), the membership function is expressed as a triplet $(f, g, h)$. The membership function $f_{A}(x)$ of the triangular fuzzy number is illustrated in figure 1 and defined as:

$f_{A}(x)= \begin{cases}0 & x<f \\ \frac{x-f}{g-f}, & f \leq x \leq g \\ \frac{h-x}{h-g}, & g \leq x \leq h\end{cases}$

The value of $x$ at $g$ gives the maximal value of $f_{A}(x)$, that is $f_{A}(x)=1$.

The value $x$ at $f$ represents the minimal grade of $f_{A}(x)$, i.e. $f_{A}(x)=0$.

The constants $f$ and $h$ stand for the lower and upper bounds of the available area data respectively. According to [13], fuzzy models using TFNs are effective for solving decision-making problems with subjective and vague available information. The TFNs are used in very practical applications because of the computational efficiency and its simplicity.

\section{Basic fuzzy sets operations}


Supposing $S=(f, g, h)$ and $T=\left(f_{1}, g_{1}, h_{1}\right)$ are two TFNs as shown in figure 1, then the basic operations on these two TFNs are as follows:

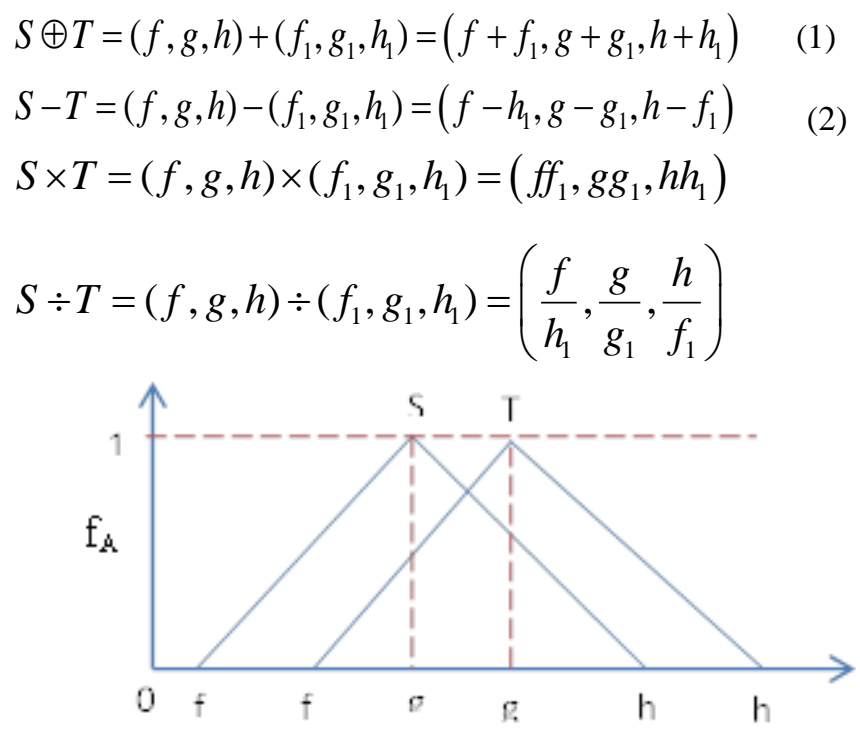

Fig. 1. Two triangular fuzzy numbers

Let $S=(f, g, h)$ and $S=\left(f_{1}, g_{1}, h_{1}\right)$ be two TFNs depicted in figure 1 . The distance between them is computed using the vertex method in eq. 6 :

$$
d(S, T)=\sqrt{1 / 3\left[\left(f-f_{1}\right)^{2}+\left(g-g_{1}\right)^{2}+\left(h-h_{1}\right)^{2}\right]}
$$

\section{Fuzzy Promethee}

The Preference Ranking Organization Method for Enrichment (PROMETHEE) is an extensively accepted outranking methods in Multiple Criteria Decision Making (MCDM). Brans and Vincke in 1985 [14] proposed the method which performs a pairwise comparison of pairs of alternatives and grades them between a $[0,1]$ interval $[15]$ using a preference function. The PROMETHEE method is preferred in ranking and selecting alternatives due to its robustness in comparing the performances of alternatives and considers it in the composite ranking. Just as in other MCDM methods, there is a fuzzy extension of the PROMETHEE method when dealing with uncertain and subjective data. Fuzzy PROMETHEE has been applied in varied areas such as health care management [16], information systems outsourcing [15], logistics [17], customer reviews [18], landslide susceptibility mapping [19] among many others. Fuzzy PROMETHEE has equally seen improvements in a number of variants, that is 
versions (PROMETHEE I, II, III, IV, V, VI), and extensions as seen in [20, 21, 22, 23].

This paper uses a combination of PROMETHEE I and II. PROMETHEE I deals with a partial ranking of alternatives $[14,21,22]$. The sum of indices, $\pi(m, l)$, initially determines the preference of alternative $m$ over the other alternatives considered. This is referred to as the 'leaving flow' $\phi^{+}(m)$, and implies the relative good performance of $m$ over the other alternatives. The alternative with the highest 'leaving flow' is pronounced the best in the evaluation. Likewise, the sum of indices, $\pi(l, m)$ is calculated to indicate the preferences of all other alternatives measured against $m$. This is also denoted as the 'entering flow' $\phi^{-}(m)$, and implies the dependency of alternative $m$ in relation to the rest of the alternatives. PROMETHEE II however introduces a net flow $\phi(m)$ which denotes the difference between the leaving and the entering flows and helps to realize a full ranking. The alternative with the highest net flow is therefore declared the best alternative.

Below is a step by step outline of definitions and formulae of the fuzzy PROMETHEE methodology culled from [14, 15, 21, 22]. The methodology is adopted in the numerical example in selecting countries for developmental aid programs.

Step 1a: Determination of linguistic Variables (criteria), linguistic terms, alternatives and decision makers

The first step is to determine the linguistic variables and its associated linguistic terms, the alternatives and number of decision makers needed in the decision making process. This set of information is what is used to construct the decision matrix. The linguistic terms are translated into fuzzy numbers and used to rate the linguistic variables. The linguistic terms are qualitative words which reflect the subjective view of an expert or decision maker about the criteria per each alternative under consideration [12, 24]. This linguistic terms with their TFNs for this paper are shown in Table 1 and 2 respectively that captures on a scale of $0-1$ the importance criteria and the alternatives.

Step 1b: Determination of Importance Criteria Weights

Decision makers determine the importance or weight of each criterion using the linguistic terms in Table 2. In equation 6 below, $w_{j}$ denotes the weight of the $j$ th criterion $C_{j}$ based on the linguistic preference assigned by a decision maker. It is noted that each weight $\tilde{w}_{j}^{k}=\left(w_{j 1}^{k}, w_{j 2}^{k}, w_{j 3}^{k}\right)$ is expressed as a TFN.

$\tilde{\boldsymbol{W}}=\left[\tilde{\boldsymbol{w}}_{1}, \tilde{\boldsymbol{w}}_{2}, \ldots, \widetilde{\boldsymbol{w}}_{n}\right], j=1,2, \ldots, n$ 
Step 2a: Construction of the fuzzy decision matrix

In a situation where $m$ alternatives and $n$ criteria are offered to $k$ decisionmakers, $\left(D_{1}, D_{2}, \ldots, D_{\mathrm{k}}\right)$ to choose the best alternative, a fuzzy MCDM problem as seen in Eq. 7 can be stated in the form of a matrix.

$$
\tilde{D}=\begin{gathered}
A_{1} \\
A_{2} \\
\vdots \\
A_{m}
\end{gathered}\left[\begin{array}{cccc}
\tilde{x}_{11} & \tilde{x}_{12} & \ldots & \tilde{x}_{1 n} \\
\tilde{x}_{21} & \tilde{x}_{22} & \cdots & \tilde{x}_{2 n} \\
\vdots & \vdots & \ddots & \vdots \\
\tilde{x}_{m 1} & \tilde{x}_{m 2} & \cdots & \tilde{x}_{m n}
\end{array}\right] \quad, i=1,2, \ldots, m ; j=1,2, \ldots, n(7)
$$

spect to criterion, $C_{j}$ both expressed in TFNs. This implies that the rating of a decision maker $k$ is $\tilde{x}_{i j}^{k}=\left(r_{i j}^{k}, u_{i j}^{k}, v_{i j}^{k}\right)$.

Step 2b: Aggregation of decisions

This stage aggregates the fuzzy weights of the criteria and the alternative ratings. This is done respectively by using the interval valued technique as illustrated in Eqs 8 and 9 below.

$$
\begin{aligned}
& \tilde{w}_{j}=\frac{1}{n}\left[\tilde{w}_{j}^{1}+\tilde{w}_{j}^{2}+\ldots,+\tilde{w}_{j}^{n}\right] \\
& \tilde{x}_{i j}=\frac{1}{n}\left[\tilde{x}_{i j}^{1}+\tilde{x}_{i j}^{2}+\ldots,+\tilde{x}_{i j}^{n}\right]
\end{aligned}
$$

\section{Step 3: Normalization of the decision matrix}

This step normalizes the aggregated fuzzy decision matrix gotten from step $2 b$ above. The normalized fuzzy decision matrix is defined as in Eq.10 and computed using Eq. 11 below. The result of the normalized matrix is still a TFN.

$$
\begin{aligned}
& \tilde{S}=\left[\tilde{s}_{i j}\right]_{m \times n}, i=1,2, \ldots, m ; j=1,2, \quad \ldots, \quad n \\
& \tilde{s}_{i j}=\left(\frac{\tilde{r}_{i j}}{v_{j}^{+}}, \frac{\tilde{u}_{i j}}{v_{j}^{+}}, \frac{\tilde{v}_{i j}}{v_{j}^{+}}\right) v_{j}^{+}=\max _{i} v_{i j}
\end{aligned}
$$

Step 4: Construction of the fuzzy preference function

The fuzzy preference function $\tilde{P}_{j}(m, n)$ is calculated to describe the decisionmakers' preference among the pairs of alternatives in this step. The usualcriterion, quasi-criterion, criterion with linear preference, level-criterion, criterion with Linear Preference and indifference area, and the Gaussian-criteria are six different types of preference functions that range between $[0,1]$ as presented by [14]. The usual-criterion function (Type I) is employed in the paper and defined in Eq. 12 below. 
$\tilde{P}_{j}(m, n)=\left\{\begin{array}{ll}0, & \tilde{s}_{m j} \leq \tilde{s}_{n j} \\ 1 & \tilde{s}_{m j}>\tilde{s}_{n j}\end{array} \quad j=1,2, \ldots, k\right.$

Step 5: Computation of weighted aggregated preference function

The weighted aggregated preference function is computed using Eq. 13 below.

$$
\tilde{\pi}(m, l)=\sum_{j=1}^{k} \tilde{P}_{j}(m, n) \tilde{w}_{j} \quad \text { (13) where } \tilde{w}_{j} \text { signifies }
$$

the importance weight of the criteria

Step 6: Computation of the leaving, entering and net flows

In this step, each alternative is related to $(n-1)$ alternatives that results in either a positive or negative flow $[16,23]$. The approach calculates the leaving, entering and net flows using Eqs 14, 15 and 16 below respectively.

Leaving flow: $\tilde{\phi}^{+}(m)=\frac{1}{n-1} \sum_{m \neq l} \tilde{\pi}(m, l), \forall m, l \in A$,

$$
\tilde{\phi}^{-}(m)=\frac{1}{n-1} \sum_{m \neq l} \tilde{\pi}(l, m),
$$

Entering flow:

where $n$ is the number of alternatives.

Step 7: Establishing ranking

This step uses PROMETHEE II for a full ranking using the net flow as shown in Eq, 16.

Net flow: $\tilde{\phi}(m)=\tilde{\phi}^{+}(m)-\tilde{\phi}^{-}(m), \forall m \in A$.

\section{Application}

The fuzzy PROMETHEE method is applied in this numerical example to evaluate countries applying for developmental aid programmes. The example adopts the OECD criteria currently used in evaluating developmental aid programs. The said set of criteria are relevance, effectiveness, efficiency, impact and sustainability presented in the framework in figure 2 below. We use the five criteria by the OECD and eight arbitrary alternatives (Countries) within the lower middle income group of the World Bank. Alternatives used in this numerical exam- 
ple are Nepal, Myanmar, Afghanistan, Somalia Benin, Chad, Ethiopia and Haiti in no particular order.

The first step of the fuzzy PROMETHEE method illustrated above is the determination of the linguistic variables, linguistic terms, the alternatives and the decision makers. Tables 1 and 2 below present the linguistic terms for the importance criteria and the alternative ratings respectively and their respective TFNs. Figure 2 further outlines the criteria and alternatives adopted in this paper.

TABLE I. LINGUISTIC SCALE FOR THE IMPORTANCE OF CRITERION

\begin{tabular}{|l|l|}
\hline Linguistic terms & Triangular fuzzy number \\
\hline Very Low $(\mathrm{VL})$ & $(0.0,0.1,0.3)$ \\
\hline Low $(\mathrm{L})$ & $(0.1,0.3,0.5)$ \\
\hline Medium(M) & $(0.3,0.5,0.7)$ \\
\hline High $(\mathrm{H})$ & $(0.5,0.7,0.9)$ \\
\hline Very High $(\mathrm{VH})$ & $(0.7,0.9,1.0)$ \\
\hline
\end{tabular}

TABLE II. LINGUISTIC TERMS FOR ALTERNATIVE RATINGS

\begin{tabular}{|l|l|}
\hline Linguistic terms & Triangular fuzzy number \\
\hline Very Low (VL) & $(0.0,0.0,2.5)$ \\
\hline Low (L) & $(0.0,2.5,5.0)$ \\
\hline High (H) & $(2.5,5.0,7.5)$ \\
\hline Very High (VH) & $(5.0,7.5,10.0)$ \\
\hline Extremely High (EH) & $(7.5,10.0,10.0)$ \\
\hline
\end{tabular}

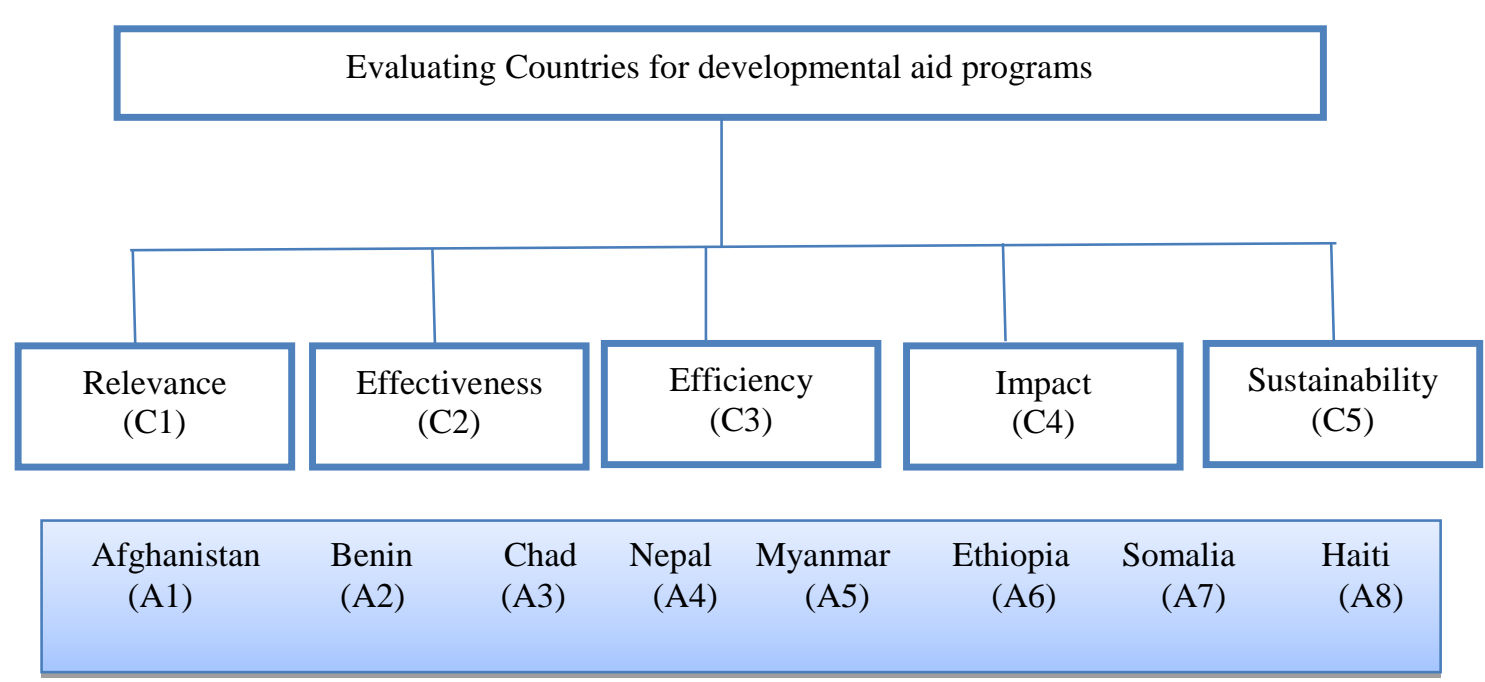

Fig. 2. Conceptual framework for selecting beneficiaries 
Using the TFNs in Table 1 and the criteria ratings by decision makers in Table 3 , the importance weights are computed by using Eq. 6 . The aggregation is done with Eq. 8. Criteria 4 (C4) is rated as the most important criterion in evaluating and selection countries for developmental aid as seen in Table 3 below. This is followed by $\mathrm{C} 3, \mathrm{C} 5, \mathrm{C} 2$ and $\mathrm{C} 1$ in that order.

TABLE III. IMPORTANCE WEIGHT CRITERION

\begin{tabular}{|l|l|l|l|l|}
\hline & D1 & D2 & D3 & Importance weight \\
\hline C1 & L & L & VL & $(0,0.233,0.5)$ \\
\hline C2 & M & L & M & $(0.1,0.433, .07)$ \\
\hline C3 & H & H & M & $(0.1,0.633,0.9)$ \\
\hline C4 & VH & VH & H & $(0.5,0.833,1)$ \\
\hline C5 & L & H & M & $(0.1,0.500,0.9)$ \\
\hline
\end{tabular}

The second step in the fuzzy PROMETHEE method is constructing a decision matrix using Eq. 7 and aggregated with Eq. 9. The 5-set linguistic terms in Table 2 (Very Low-VL; Low-L; High-H; Very High-VH; Extremely High-EH) were used by the decision makers in assessing countries for developmental aid. Table 3 presents the decision matrix of the three decision makers used in this example.

TABLE IV. ALternative RATINGS By DECISION-MAKERS

\begin{tabular}{|c|c|c|c|c|c|c|c|c|}
\hline & \multicolumn{8}{|c|}{ Decision maker 1} \\
\hline & A1 & A2 & A3 & A4 & A5 & A6 & A7 & A8 \\
\hline $\mathrm{C} 1$ & VL & $\mathrm{L}$ & $\mathrm{H}$ & $\mathrm{VH}$ & $\mathrm{H}$ & VL & $\mathrm{EH}$ & $\mathrm{H}$ \\
\hline $\mathrm{C} 2$ & $\mathrm{H}$ & $\mathrm{H}$ & $\mathrm{VH}$ & $\mathrm{H}$ & VL & $\mathrm{L}$ & $\mathrm{EH}$ & $\mathrm{H}$ \\
\hline C3 & $\mathrm{L}$ & VL & $\mathrm{L}$ & $\mathrm{H}$ & $\mathrm{H}$ & $\mathrm{H}$ & $\mathrm{VH}$ & $\mathrm{L}$ \\
\hline $\mathrm{C} 4$ & $\mathrm{H}$ & VH & $\mathrm{L}$ & $\mathrm{EH}$ & VL & $\mathrm{L}$ & $\mathrm{VH}$ & $\mathrm{L}$ \\
\hline \multirow[t]{3}{*}{$\mathrm{C} 5$} & VL & VH & $\mathrm{L}$ & $\mathrm{H}$ & $\mathrm{L}$ & VL & VH & $\mathrm{H}$ \\
\hline & \multicolumn{8}{|c|}{ Decision maker 2} \\
\hline & A1 & A2 & A3 & A4 & A5 & A6 & A7 & A8 \\
\hline $\mathrm{C} 1$ & VH & $\mathrm{H}$ & VH & $\mathrm{L}$ & VL & $\mathrm{H}$ & $\mathrm{EH}$ & VH \\
\hline $\mathrm{C} 2$ & VL & $\mathrm{EH}$ & $\mathrm{H}$ & $\mathrm{VH}$ & $\mathrm{L}$ & $\mathrm{H}$ & VH & $\mathrm{H}$ \\
\hline C3 & EH & $\mathrm{H}$ & $\mathrm{L}$ & VL & $\mathrm{H}$ & $\mathrm{VH}$ & $\mathrm{VH}$ & $\mathrm{H}$ \\
\hline $\mathrm{C} 4$ & VL & $\mathrm{H}$ & $\mathrm{L}$ & $\mathrm{H}$ & $\mathrm{H}$ & VH & $\mathrm{VH}$ & $\mathrm{L}$ \\
\hline \multirow[t]{3}{*}{$\mathrm{C} 5$} & $\mathrm{EH}$ & $\mathrm{H}$ & $\mathrm{L}$ & $\mathrm{VH}$ & $\mathrm{EH}$ & $\mathrm{H}$ & $\mathrm{EH}$ & $\mathrm{EH}$ \\
\hline & \multicolumn{8}{|c|}{ Decision maker 3} \\
\hline & $\mathrm{A} 1$ & $\mathrm{~A} 2$ & A3 & A4 & A5 & A6 & A7 & A8 \\
\hline $\mathrm{C} 1$ & EH & $\mathrm{H}$ & $\mathrm{H}$ & VL & $\mathrm{L}$ & $\mathrm{L}$ & $\mathrm{VH}$ & $\mathrm{EH}$ \\
\hline $\mathrm{C} 2$ & $\mathrm{H}$ & VH & $\mathrm{H}$ & $\mathrm{L}$ & $\mathrm{L}$ & $\mathrm{H}$ & VH & $\mathrm{L}$ \\
\hline C3 & $\mathrm{H}$ & $\mathrm{EH}$ & VL & $\mathrm{L}$ & $\mathrm{VH}$ & $\mathrm{L}$ & $\mathrm{VH}$ & $\mathrm{H}$ \\
\hline $\mathrm{C} 4$ & $\mathrm{H}$ & VL & $\mathrm{H}$ & $\mathrm{H}$ & $\mathrm{EH}$ & $\mathrm{H}$ & $\mathrm{VH}$ & VL \\
\hline C5 & VL & $\mathrm{L}$ & $\mathrm{VH}$ & $\mathrm{EH}$ & $\mathrm{L}$ & $\mathrm{L}$ & $\mathrm{VH}$ & $\mathrm{H}$ \\
\hline
\end{tabular}

The third step normalized the aggregated decision matrix using Eq. 11. Computation of the preference function to describe the decision-makers' aggregated preference between pairs of alternatives is presented in the fourth step. As indicated above, the paper adopted the 'usual criterion' presented in Eq. 12 for the computation. The pairwise preferences are presented in Table 5 below. 
TABLE V. PAIRWISE PREFERENCE FunCtions For the ALternatives

\begin{tabular}{|c|c|c|c|c|c|}
\hline & C1 & $\mathrm{C} 2$ & C3 & $\mathrm{C4}$ & C5 \\
\hline $\mathrm{P}(\mathrm{A} 1, \mathrm{~A} 2)$ & 1 & 0 & 0 & 0 & 0 \\
\hline $\mathrm{P}(\mathrm{A} 1, \mathrm{~A} 3)$ & 0 & 0 & 1 & 0 & 0 \\
\hline $\mathrm{P}(\mathrm{A} 1, \mathrm{~A} 4)$ & 0 & 0 & 1 & 0 & 0 \\
\hline $\mathrm{P}(\mathrm{A} 1, \mathrm{~A} 5)$ & 1 & 1 & 0 & 0 & 0 \\
\hline $\mathrm{P}(\mathrm{A} 1, \mathrm{~A} 6)$ & 1 & 0 & 0 & 0 & 1 \\
\hline $\mathrm{P}(\mathrm{A} 1, \mathrm{~A} 7)$ & 0 & 0 & 0 & 0 & 0 \\
\hline $\mathrm{P}(\mathrm{A} 1, \mathrm{~A} 8)$ & 0 & 0 & 1 & 1 & 0 \\
\hline $\mathrm{P}(\mathrm{A} 2, \mathrm{~A} 1)$ & 0 & 1 & 0 & 1 & 0 \\
\hline $\mathrm{P}(\mathrm{A} 2, \mathrm{~A} 3)$ & 0 & 0 & 1 & 1 & 0 \\
\hline $\mathrm{P}(\mathrm{A} 2, \mathrm{~A} 4)$ & 0 & 0 & 1 & 0 & 0 \\
\hline $\mathrm{P}(\mathrm{A} 2, \mathrm{~A} 5)$ & 0 & 1 & 0 & 0 & 0 \\
\hline $\mathrm{P}(\mathrm{A} 2, \mathrm{~A} 6)$ & 0 & 1 & 0 & 0 & 1 \\
\hline $\mathrm{P}(\mathrm{A} 2, \mathrm{~A} 7)$ & 0 & 0 & 0 & 0 & 0 \\
\hline $\mathrm{P}(\mathrm{A} 2, \mathrm{~A} 8)$ & 0 & 1 & 1 & 1 & 0 \\
\hline $\mathrm{P}(\mathrm{A} 3, \mathrm{~A} 1)$ & 1 & 1 & 1 & 1 & 1 \\
\hline $\mathrm{P}(\mathrm{A} 3, \mathrm{~A} 2)$ & 0 & 1 & 1 & 1 & 1 \\
\hline $\mathrm{P}(\mathrm{A} 3, \mathrm{~A} 4)$ & 0 & 0 & 0 & 0 & 0 \\
\hline $\mathrm{P}(\mathrm{A} 3, \mathrm{~A} 5)$ & 1 & 1 & 0 & 0 & 0 \\
\hline $\mathrm{P}(\mathrm{A} 3, \mathrm{~A} 6)$ & 1 & 1 & 0 & 0 & 1 \\
\hline $\mathrm{P}(\mathrm{A} 3, \mathrm{~A} 7)$ & 0 & 0 & 0 & 0 & 0 \\
\hline $\mathrm{P}(\mathrm{A} 3, \mathrm{~A} 8)$ & 0 & 1 & 0 & 1 & 0 \\
\hline $\mathrm{P}(\mathrm{A} 4, \mathrm{~A} 1)$ & 0 & 1 & 0 & 1 & 0 \\
\hline $\mathrm{P}(\mathrm{A} 4, \mathrm{~A} 2)$ & 1 & 0 & 0 & 0 & 0 \\
\hline $\mathrm{P}(\mathrm{A} 4, \mathrm{~A} 3)$ & 0 & 0 & 1 & 1 & 0 \\
\hline $\mathrm{P}(\mathrm{A} 4, \mathrm{~A} 5)$ & 1 & 1 & 0 & 0 & 0 \\
\hline $\mathrm{P}(\mathrm{A} 4, \mathrm{~A} 6)$ & 1 & 1 & 0 & 0 & 0 \\
\hline $\mathrm{P}(\mathrm{A} 4, \mathrm{~A} 7)$ & 0 & 0 & 0 & 0 & 0 \\
\hline $\mathrm{P}(\mathrm{A} 4, \mathrm{~A} 8)$ & 0 & 1 & 0 & 1 & 0 \\
\hline $\mathrm{P}(\mathrm{A} 5, \mathrm{~A} 1)$ & 0 & 0 & 0 & 1 & 0 \\
\hline $\mathrm{P}(\mathrm{A} 5, \mathrm{~A} 2)$ & 0 & 0 & 0 & 0 & 0 \\
\hline $\mathrm{P}(\mathrm{A} 5, \mathrm{~A} 3)$ & 0 & 0 & 1 & 1 & 0 \\
\hline $\mathrm{P}(\mathrm{A} 5, \mathrm{~A} 4)$ & 0 & 0 & 1 & 0 & 0 \\
\hline $\mathrm{P}(\mathrm{A} 5, \mathrm{~A} 6)$ & 0 & 0 & 0 & 0 & 1 \\
\hline $\mathrm{P}(\mathrm{A} 5, \mathrm{~A} 7)$ & 0 & 0 & 0 & 0 & 0 \\
\hline $\mathrm{P}(\mathrm{A} 5, \mathrm{~A} 8)$ & 0 & 0 & 1 & 1 & 0 \\
\hline
\end{tabular}




\begin{tabular}{|l|l|l|l|l|l|}
\hline $\mathrm{P}(\mathrm{A} 6, \mathrm{~A} 1)$ & 0 & 0 & 0 & 1 & 0 \\
\hline $\mathrm{P}(\mathrm{A} 6, \mathrm{~A} 2)$ & 0 & 0 & 0 & 0 & 0 \\
\hline $\mathrm{P}(\mathrm{A} 6, \mathrm{~A} 3)$ & 0 & 0 & 1 & 1 & 0 \\
\hline $\mathrm{P}(\mathrm{A} 6, \mathrm{~A} 4)$ & 0 & 0 & 1 & 0 & 0 \\
\hline $\mathrm{P}(\mathrm{A} 6, \mathrm{~A} 5)$ & 0 & 1 & 0 & 0 & 0 \\
\hline $\mathrm{P}(\mathrm{A} 6, \mathrm{~A} 7)$ & 0 & 0 & 0 & 0 & 0 \\
\hline $\mathrm{P}(\mathrm{A} 6, \mathrm{~A} 8)$ & 0 & 0 & 1 & 1 & 0 \\
\hline $\mathrm{P}(\mathrm{A} 7, \mathrm{~A} 1)$ & 0 & 1 & 0 & 1 & 0 \\
\hline $\mathrm{P}(\mathrm{A} 7, \mathrm{~A} 2)$ & 1 & 0 & 0 & 0 & 0 \\
\hline $\mathrm{P}(\mathrm{A} 7, \mathrm{~A} 3)$ & 0 & 0 & 1 & 1 & 0 \\
\hline $\mathrm{P}(\mathrm{A} 7, \mathrm{~A} 4)$ & 0 & 0 & 1 & 0 & 0 \\
\hline $\mathrm{P}(\mathrm{A} 7, \mathrm{~A} 5)$ & 1 & 1 & 0 & 0 & 1 \\
\hline $\mathrm{P}(\mathrm{A} 7, \mathrm{~A} 6)$ & 1 & 1 & 0 & 0 & 1 \\
\hline $\mathrm{P}(\mathrm{A} 7, \mathrm{~A} 8)$ & 0 & 1 & 1 & 1 & 0 \\
\hline $\mathrm{P}(\mathrm{A} 8, \mathrm{~A} 1)$ & 0 & 0 & 0 & 0 & 0 \\
\hline $\mathrm{P}(\mathrm{A} 8, \mathrm{~A} 2)$ & 1 & 0 & 0 & 0 & 0 \\
\hline $\mathrm{P}(\mathrm{A} 8, \mathrm{~A} 3)$ & 0 & 0 & 1 & 0 & 0 \\
\hline $\mathrm{P}(\mathrm{A} 8, \mathrm{~A} 4)$ & 0 & 0 & 0 & 0 & 0 \\
\hline $\mathrm{P}(\mathrm{A} 8, \mathrm{~A} 5)$ & 0 & 1 & 0 & 0 & 0 \\
\hline $\mathrm{P}(\mathrm{A} 8, \mathrm{~A} 6)$ & 1 & 0 & 0 & 0 & 1 \\
\hline $\mathrm{P}(\mathrm{A} 8, \mathrm{~A} 7)$ & 0 & 0 & 0 & 0 & 0 \\
\hline
\end{tabular}

The weighted aggregated preference function is then calculated in step five using Eq. 13 and presented below in Table 6.

TABLE VI. WeIGHTED AgGREgated PREFERENCE FunCTION

\begin{tabular}{|l|l|l|l|l|l|l|l|l|}
\hline & $\mathbf{A 1}$ & $\mathbf{A 2}$ & $\mathbf{A 3}$ & $\mathbf{A 4}$ & $\mathbf{A 5}$ & $\mathbf{A 6}$ & $\mathbf{A 7}$ & $\mathbf{A 8}$ \\
\hline $\mathbf{A 1}$ & & 0.733 & 1.633 & 1.633 & 1.970 & 2.230 & 0 & 3.970 \\
\hline $\mathbf{A 2}$ & 3.567 & & 3.967 & 1.633 & 1.230 & 2.730 & 0 & 5.200 \\
\hline $\mathbf{A 3}$ & 7.433 & 6.7 & & 0 & 1.970 & 3.470 & 0 & 3.570 \\
\hline $\mathbf{A 4}$ & 3.567 & 0.733 & 3.967 & & 1.970 & 1.970 & 0 & 3.570 \\
\hline $\mathbf{A 5}$ & 2.333 & 0 & 3.967 & 1.633 & & 1.500 & 0 & 3.970 \\
\hline $\mathbf{A 6}$ & 2.333 & 0 & 3.967 & 1.633 & 1.230 & & 0 & 3.970 \\
\hline $\mathbf{A 7}$ & 3.567 & 0.733 & 3.967 & 1.633 & 3.470 & 3.470 & & 5.2000 \\
\hline $\mathbf{A 8}$ & 0 & 0.733 & 1.633 & 0 & 1.230 & 2.230 & 0 & \\
\hline
\end{tabular}

Step six computes the leaving, entering and net flows Eq. 14, 15 and 16 respectively. Table 7 below presents the computed leaving, entering, net flows and the alternative ranking. Figure 3 also presents the partial preorder outranking and the preorder outranking giving alternative 7 (A7) as the best alternative. 
TABLE VII. THE LEAVING/ENTERING, NET FLOWS AND ALTERNATIVES RANKING

\begin{tabular}{lllll}
\hline & $\begin{array}{c}\text { Leaving Flow } \\
\left(\phi^{+}(m)\right)\end{array}$ & $\begin{array}{l}\text { Entering } \\
\text { Flow }\left(\phi^{-}(m)\right)\end{array}$ & Net Flow & Ranking \\
\hline A1 & 1.7381 & 3.257143 & -1.51905 & 7 \\
A2 & 2.61905 & 1.37619 & 1.24286 & 2 \\
A3 & 3.30476 & 3.30000 & 0.00476 & 5 \\
A4 & 2.25238 & 1.166667 & 1.08571 & 3 \\
A5 & 1.91429 & 1.866667 & 0.04762 & 4 \\
A6 & 1.87619 & 2.514286 & -0.63810 & 6 \\
A7 & 3.14762 & 0 & 3.14762 & 1 \\
A8 & 0.83333 & 4.204762 & -3.37143 & 8 \\
\hline
\end{tabular}

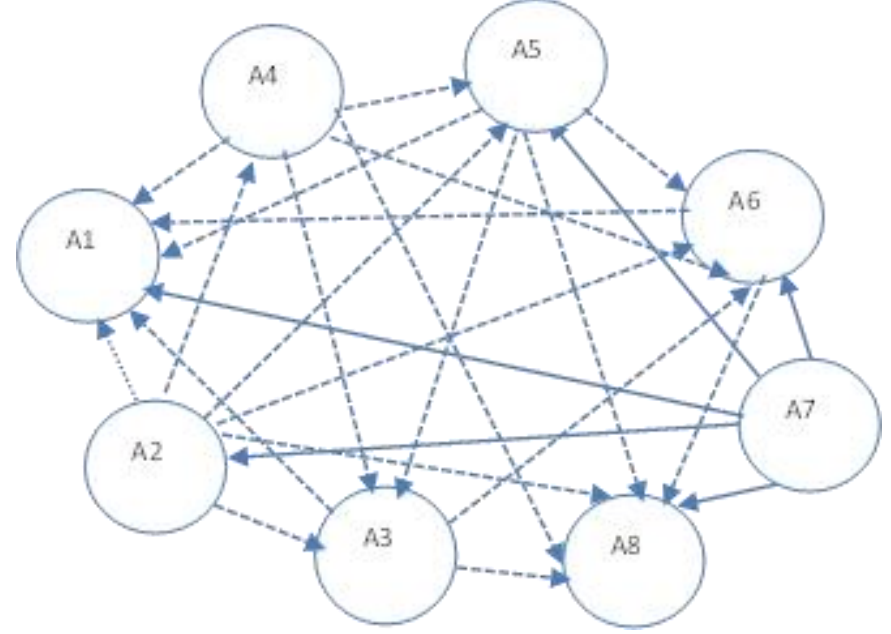

(a)

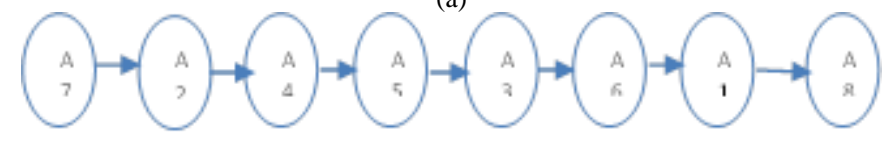

(b)

Fig. 3. (a) Partial preorder outranking; (b) Full preorder outranking

The partial preorder outranking is denoted by Figure $3 \mathrm{a}$ as a partial ranking of alternatives while Figure $3 b$ is the full ranking that signifies the best alternative with chronological succeeding alternatives.

\section{v. COMPARATIVE ANALYSIS}

\section{A. FUZZY TOPSIS}

Since Yoon and Hwang (1995) introduced the Technique for Order Preference by Similarity to Ideal Solution (TOPSIS) method, it has become one of the in- 
dustry standards widely applied in the area of Multiple Criteria Decision Making (MCDM). To determine the best alternative measured against sets of criteria, the TOPSIS method does this by introducing concurrently the shortest distance from the Fuzzy Positive Ideal Solution (FPIS) and the farthest distance from the Fuzzy Negative Ideal Solution (FNIS). The FNIS works by maximizing the cost criteria and minimizing the benefit criteria, whiles the FPIS seeks to maximize the benefit criteria whiles minimizing the cost criteria (Afful-Dadzie et al 2014). The alternatives are evaluated and subsequently selected by ranking their relative closeness combining two distance measures. The numerical example used above is applied in TOPSIS to compare the ranking of the methods.

The numerical example uses the same criteria, number of decision makers and alternatives as used in PROMETHEE. However, the TOPSIS method and the procedure in coming out with the ranking of the alternatives is quite different.

The judgements on the importance weights are made by the three decision makers, aggregated using the graded mean integration method is used to aggregate each criterion while the Center of Area (COA) technique is applied in calculating the BNP. The criteria weights are presented in Table 8 below.

\begin{tabular}{|c|c|c|c|c|}
\hline \multicolumn{5}{|c|}{ TABLE VIII. WEIGHTS OF EACH CRITERIA } \\
\hline C1 & 0 & 0.233 & 0.5 & 0.244 \\
\hline C2 & 0.1 & 0.433 & 0.7 & 0.411 \\
\hline C3 & 0.1 & 0.633 & 0.9 & 0.544 \\
\hline C4 & 0.5 & 0.833 & 1 & 0.778 \\
\hline C5 & 0.1 & 0.500 & 0.9 & 0.500 \\
\hline
\end{tabular}

The alternative ratings produced by the three decision makers in Table 4 are aggregated before normalization. The linguistic terms in Table 2 are applied to the alternative ratings and aggregated using the graded mean integration. The results of the aggregated alternative ratings is shown in Table 9.

\begin{tabular}{|c|c|c|c|c|c|c|c|c|}
\hline & A1 & A2 & A3 & A4 & A5 & A6 & A7 & A8 \\
\hline $\mathrm{C} 1$ & 10.05 .810 .0 & 0.04 .27 .5 & $2.55 .8 \quad 10.0$ & $0.03 .3 \quad 10.0$ & 0.02 .57 .5 & 0.02 .57 .5 & $\begin{array}{llll}5.0 & 9.2 & 10.0\end{array}$ & 2.57 .510 .0 \\
\hline $\mathrm{C} 2$ & $\begin{array}{l}2 \\
\end{array} .03 .37 .5$ & $2.57 .5 \quad 10.0$ & $\begin{array}{llll}2.5 & 5.8 & 10.0\end{array}$ & $\begin{array}{llll}0.0 & 5.0 & 10.0\end{array}$ & 0.01 .75 .0 & 0.04 .27 .5 & $\begin{array}{llll}5.0 & 8.3 & 10.0\end{array}$ & 0.04 .27 .5 \\
\hline C3 & $\begin{array}{llll}3 & 5.0 & 10.0\end{array}$ & $\begin{array}{llll}0.0 & 5.0 & 10.0\end{array}$ & 0.01 .75 .0 & 0.02 .57 .5 & 2.55 .810 .0 & 0.05 .010 .0 & 5.07 .510 .0 & 0.04 .27 .5 \\
\hline $\mathrm{C} 4$ & 40.03 .37 .5 & $0.04 .2 \begin{array}{lll}0.0 & 10.0\end{array}$ & 0.03 .37 .5 & 2.56 .710 .0 & $\left|\begin{array}{lll}0.0 & 5.0 & 10.0\end{array}\right|$ & $\begin{array}{llll}0.0 & 5.0 & 10.0\end{array}$ & $\begin{array}{lll}5.0 & 7.5 & 10.0\end{array}$ & 0.01 .75 .0 \\
\hline $\mathrm{C} 5$ & $5 \mid \begin{array}{lll}5.0 & 3.3 & 10.0\end{array}$ & $\begin{array}{llll}0.0 & 5.0 & 10.0\end{array}$ & 0.04 .210 .0 & 2.57 .510 .0 & $\begin{array}{llll}0.0 & 5.0 & 10.0\end{array}$ & 0.02 .57 .5 & $\begin{array}{llll}5.0 & 8.3 & 10.0\end{array}$ & 2.56 .710 .0 \\
\hline
\end{tabular}

The next step is the normalization of the aggregated decision matrix using Eq. 17 below. The results of the normalized decision matrix is shown in Table 10. 


$$
\tilde{r}_{i j}=\left(\frac{\tilde{f}_{i j}}{h_{j}^{+}}, \frac{\tilde{g}_{i j}}{h_{j}^{+}}, \frac{\tilde{h}_{i j}}{h_{j}^{+}}\right) h_{j}^{+}=\max _{i} h_{i j}
$$

TABLE X: NORMALIZED FUZZY DECISION MATRIX

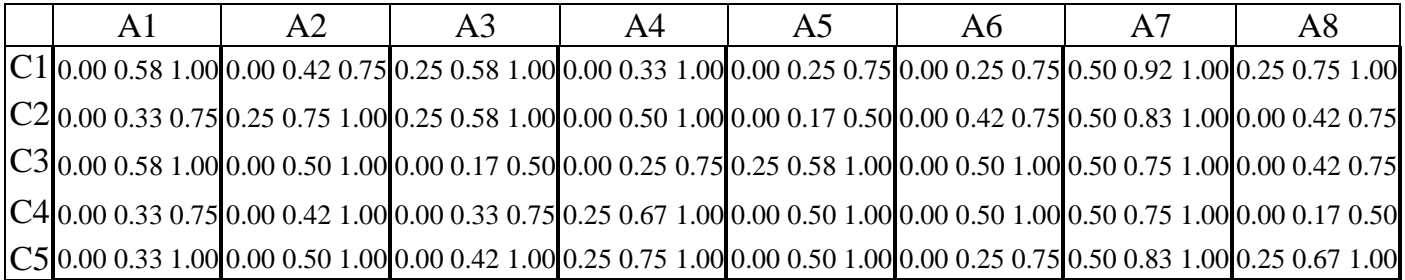

The fuzzy normalized matrix is then weighted using the BNP values generated in Table 11. The weighted normalized fuzzy decision matrix is presented in Table 11 .

TABLE XI: WEIGHTED NORMALIZED FUZZY DECISION MATRIX

\begin{tabular}{|c|c|c|c|c|c|c|c|c|}
\hline & A1 & $\mathrm{A} 2$ & A3 & A4 & A5 & A6 & A7 & A8 \\
\hline 1 & 0.000 .14 & 0.000 .10 & 000.140 .50 & 000.080 .50 & 0.000 .060 .38 & $\begin{array}{lll}0.00 & 0.06 & 0.38\end{array}$ & $\begin{array}{llll}0.00 & 0.21 & 0.50\end{array}$ & $\begin{array}{llll}0.00 & 0.18 & 0.5\end{array}$ \\
\hline $\mathrm{C} 2$ & & & & & & $\begin{array}{llll}0.00 & 0.18 & 0.53\end{array}$ & & \\
\hline C3 & & & & 0.000 .16 & & & & \\
\hline $\mathrm{C} 4$ & 0.00 & & $\begin{array}{llll}0.00 & 0.28 & 0.75\end{array}$ & & .000 .4 & 0.000 .42 & & 0.00 \\
\hline 5 & .000 .170 .90 & $\begin{array}{llll}0.00 & 0.25 & 0.90\end{array}$ & $\begin{array}{llll}0.00 & 0.21 & 0.90\end{array}$ & $\begin{array}{llll}0.03 & 0.38 & 0.90\end{array}$ & $\begin{array}{llll}0.00 & 0.25 & 0.90\end{array}$ & $\begin{array}{llll}0.00 & 0.13 & 0.68\end{array}$ & $\begin{array}{llll}0.05 & 0.42 & 0.90\end{array}$ & $\begin{array}{llll}0.03 & 0.33 & 0.9\end{array}$ \\
\hline
\end{tabular}

The fuzzy positive and fuzzy negative ideal solutions are determined. The relative closeness coefficient is calculated based on the fuzzy positive and fuzzy negative ideal solutions. Table 12 presents the distance measurement including the associated ranks of all the alternatives used.

TABLE XII: THE DISTANCE MEASUREMENT

\begin{tabular}{|l|l|l|l|c|}
\hline & $d_{i}^{+}$ & $d_{i}^{-}$ & $C C_{i}$ & Rank \\
\hline A1 & 3.79 & 2.17 & 0.3637 & 4 \\
\hline A2 & 3.68 & 2.37 & 0.3919 & 3 \\
\hline A3 & 3.85 & 1.99 & 0.3410 & 7 \\
\hline A5 & 3.61 & 2.34 & 0.3939 & 2 \\
\hline A6 & 3.81 & 2.15 & 0.3610 & 5 \\
\hline A7 & 3.83 & 2.11 & 0.3557 & 6 \\
\hline A8 & 3.23 & 2.63 & 0.4484 & 1 \\
\hline
\end{tabular}


Based on the results in Table 12, alternative A7 is ranked top followed by A4 and A2 respectively.

\section{B. FUZZY VIKOR}

The 'VlseKriterijumska Optimizacija I Kompromisno Resenje' technique in MCDM consist of a multi-criteria optimization and compromise solution. The technique was extended in the fuzzy environment so as to address subjectivity and impreciseness in data. In this technique, a compromise ranking is established using weight intervals, the fuzzy best and fuzzy worst solutions. The fuzzy VIKOR method deals with ranking of alternatives with multi-conflicting or non-commensurable criteria (Afful-Dadzie et al, 2015).

Adapting the same criteria, number of decision makers, alternatives and fuzzy decisions, a numerical example is presented below for comparison with the fuzzy PROMETHEE and fuzzy TOPSIS results above.

Based on the aggregated fuzzy decisions in Table 9, the fuzzy best and fuzzy worst values are calculated using Eqns 18 and 19. The results are stated in Table 13.

$$
\begin{aligned}
& \tilde{f}_{j}^{+}=\max _{i} \tilde{x}_{i j}, f_{j}^{-}=\min _{i} \tilde{x}_{i j}, \text { for } j \in B \\
& \tilde{f}_{j}^{+}=\min _{i} \tilde{x}_{i j}, f_{j}^{-}=\max _{i} \tilde{x}_{i j}, \text { for } j \in C
\end{aligned}
$$

\begin{tabular}{|c|c|c|c|c|c|}
\hline \multicolumn{3}{|c|}{ Fuzzy Best Value } & \multicolumn{3}{|c|}{ Fuzzy worst value } \\
\hline 5.00 & 9.17 & 10.00 & 0.00 & 2.50 & 7.50 \\
\hline 5.00 & 8.33 & 10.00 & 0.00 & 1.67 & 5.00 \\
\hline 5.00 & 7.50 & 10.00 & 0.00 & 2.50 & 5.00 \\
\hline 5.00 & 7.50 & 10.00 & 0.00 & 1.67 & 5.00 \\
\hline 5.00 & 8.33 & 10.00 & 0.00 & 2.50 & 7.50 \\
\hline
\end{tabular}

The fuzzy decisions are then normalized and weighted using Eqns 20 and 21. The results are detailed in Tables 14 and 15 below.

$$
\begin{aligned}
& \tilde{d}_{i j}=\left(\tilde{f}_{j}^{*}-\tilde{x}_{i j}\right) /\left(c_{j}^{*}-a_{j}^{\circ}\right) \quad \text { for } j \in B \\
& \tilde{d}_{i j}=\left(\tilde{x}_{i j}-\tilde{f}_{j}^{*}\right) /\left(c_{j}^{\circ}-a_{j}^{*}\right) \quad \text { for } j \in C
\end{aligned}
$$

\begin{tabular}{|c|c|c|c|c|c|c|c|c|c|c|c|c|}
\hline \multicolumn{3}{|c|}{$A 1-f j^{*}-x i j$} & \multicolumn{3}{|c|}{$A 2-f j^{*}-x i j$} & \multicolumn{3}{|c|}{ A3-fj*-xij } & \multicolumn{3}{|c|}{ A4- fj*-xij } & \\
\hline-2.50 & 6.67 & 10.00 & -2.50 & 5.00 & 10.00 & -5.00 & 3.33 & 10.00 & -5.00 & 5.83 & 10.00 & $\mathrm{C} 1$ \\
\hline 0.00 & 6.67 & 10.00 & -5.00 & 0.83 & 7.50 & -2.50 & 5.00 & 10.00 & -5.00 & 3.33 & 10.00 & $\mathrm{C} 2$ \\
\hline
\end{tabular}

where $B$ is the benefit criteria and $C$, the cost criteria.

TABLE 14A. NORMALIZED FUZZY DIFFERENCE 


\begin{tabular}{|l|l|l|l|l|l|l|l|l|l|l|l|l|}
\hline-5.00 & 1.67 & 7.50 & -5.00 & 2.50 & 10.00 & -5.00 & 1.67 & 10.00 & -2.50 & 5.00 & 10.00 & C3 \\
\hline-5.00 & 2.50 & 10.00 & -5.00 & 3.33 & 10.00 & -2.50 & 4.17 & 10.00 & -5.00 & 0.83 & 7.50 & C4 \\
\hline-5.00 & 3.33 & 10.00 & -5.00 & 3.33 & 10.00 & -5.00 & 5.00 & 10.00 & -5.00 & 0.83 & 7.50 & C5 \\
\hline
\end{tabular}

TABLE 14B. NORMALIZED FUZZY DIFFERENCE

\begin{tabular}{|c|c|l|l|l|l|l|l|l|l|l|l|l|}
\hline \multicolumn{3}{|c|}{ A5- fj ${ }^{*}$-xij } & \multicolumn{3}{c|}{ A6- fj*-xij } & \multicolumn{3}{c|}{ A7- fj ${ }^{*}$-xij } & \multicolumn{3}{c|}{ A8- fj*-xij } & \multicolumn{1}{c|}{} \\
\hline-2.50 & 6.67 & 10.00 & -5.00 & 3.33 & 7.50 & -5.00 & 0.00 & 5.00 & -5.00 & 1.67 & 7.50 & C1 \\
\hline-2.50 & 4.17 & 10.00 & -5.00 & 2.50 & 7.50 & -5.00 & 0.00 & 5.00 & -2.50 & 4.17 & 10.00 & C2 \\
\hline-5.00 & 2.50 & 10.00 & 0.00 & 5.83 & 10.00 & -5.00 & 0.00 & 5.00 & -2.50 & 3.33 & 10.00 & C3 \\
\hline-5.00 & 2.50 & 10.00 & -2.50 & 4.17 & 10.00 & -5.00 & 0.00 & 5.00 & 0.00 & 5.83 & 10.00 & C4 \\
\hline-2.50 & 5.83 & 10.00 & -5.00 & 4.17 & 10.00 & -5.00 & 0.00 & 5.00 & -5.00 & 1.67 & 7.50 & C5 \\
\hline
\end{tabular}

TABLE 15A. WEIGHTED NORMALIZED FUZZY DIFFERENCE

\begin{tabular}{|l|l|l|l|l|l|l|l|l|l|l|l|l|}
\hline C1 & Weighted A1 & 1.0 & 5.0 & 0.0 & 1.2 & 5.0 & 0.0 & 0.8 & 5.0 & 0.0 & 1.4 & 5.0 \\
\hline C2 & 0.0 & 2.9 & 7.0 & -0.5 & 0.4 & 5.3 & -0.3 & 2.2 & 7.0 & -0.5 & 1.4 & 7.0 \\
\hline C3 & -0.5 & 1.1 & 6.8 & -0.5 & 1.6 & 9.0 & -0.5 & 1.1 & 9.0 & -0.3 & 3.2 & 9.0 \\
\hline C4 & -2.5 & 2.1 & 10.0 & -2.5 & 2.8 & 10.0 & -1.3 & 3.5 & 10.0 & -2.5 & 0.7 & 7.5 \\
\hline C5 & -0.5 & 1.7 & 9.0 & -0.5 & 1.7 & 9.0 & -0.5 & 2.5 & 9.0 & -0.5 & 0.4 & 6.8 \\
\hline
\end{tabular}

TABLE 15B. WEIGHTED NORMALIZED FUZZY DIFFERENCE

\begin{tabular}{|l|l|l|l|l|l|l|l|l|l|l|l|l|l|}
\hline & \multicolumn{9}{|c|}{ Weighted A5 } & \multicolumn{3}{|c|}{ Weighted A6 } & \multicolumn{3}{|c|}{ Weighted A7 } & \multicolumn{3}{|c|}{ Weighted A8 } \\
\hline C1 & 0.0 & 1.6 & 5.0 & 0.0 & 0.8 & 3.8 & 0.0 & 0.0 & 2.5 & 0.0 & 0.4 & 3.8 \\
\hline C2 & -0.3 & 1.8 & 7.0 & -0.5 & 1.1 & 5.3 & -0.5 & 0.0 & 3.5 & -0.3 & 1.8 & 7.0 \\
\hline C3 & -0.5 & 1.6 & 9.0 & 0.0 & 3.7 & 9.0 & -0.5 & 0.0 & 4.5 & -0.3 & 2.1 & 9.0 \\
\hline C4 & -2.5 & 2.1 & 10.0 & -1.3 & 3.5 & 10.0 & -2.5 & 0.0 & 5.0 & 0.0 & 4.9 & 10.0 \\
\hline C5 & -0.3 & 2.9 & 9.0 & -0.5 & 2.1 & 9.0 & -0.5 & 0.0 & 4.5 & -0.5 & 0.8 & 6.8 \\
\hline
\end{tabular}

Computing the separation measures of $\tilde{S}_{i}$ and $\tilde{R}_{i}$ are calculated from the fuzzy best and fuzzy worst values. The results of the measures is presented in Tables 16 below.

TABLE 16. SEPARATION MEASURES OF $\tilde{S}_{i}$ AND $\tilde{R}_{i}$
\begin{tabular}{|l|l|l|l|l|l|l|l|l|l|l|l|l|l|}
\hline & \multicolumn{3}{|c|}{ dA1 } & \multicolumn{3}{|c|}{ dA2 } & \multicolumn{3}{c|}{ dA3 } & \multicolumn{3}{c|}{ dA4 } \\
\hline C1 & 0.00 & 0.16 & 0.50 & 0.00 & 0.12 & 0.50 & 0.00 & 0.08 & 0.50 & 0.00 & 0.14 & 0.50 \\
\hline C2 & 0.00 & 0.29 & 0.70 & -0.05 & 0.04 & 0.53 & -0.03 & 0.22 & 0.70 & -0.05 & 0.14 & 0.70 \\
\hline C 3 & -0.05 & 0.11 & 0.68 & -0.05 & 0.16 & 0.90 & -0.05 & 0.11 & 0.90 & -0.03 & 0.32 & 0.90 \\
\hline C4 & -0.25 & 0.21 & 1.00 & -0.25 & 0.28 & 1.00 & -0.13 & 0.35 & 1.00 & -0.25 & 0.07 & 0.75 \\
\hline C5 & -0.05 & 0.17 & 0.90 & -0.05 & 0.17 & 0.90 & -0.05 & 0.25 & 0.90 & -0.05 & 0.04 & 0.68 \\
\hline$\tilde{S}_{j}$ & -0.35 & 0.93 & 3.78 & -0.40 & 0.76 & 3.83 & -0.25 & 1.00 & 4.00 & -0.38 & 0.71 & 3.53 \\
\hline$\tilde{R}_{j}$ & 0.00 & 0.29 & 1.00 & 0.00 & 0.28 & 1.00 & 0.00 & 0.35 & 1.00 & 0.00 & 0.32 & 0.90 \\
\hline
\end{tabular}




\begin{tabular}{|l||l|l|l|l|l|l|l|l|l|l|l|l|}
\hline \multicolumn{1}{|c||}{} & \multicolumn{3}{|c|}{ dA5 } & \multicolumn{3}{c|}{ dA6 } & \multicolumn{3}{c|}{ dA7 } & \multicolumn{3}{c|}{ dA8 } \\
\hline C1 & 0.00 & 0.16 & 0.50 & 0.00 & 0.08 & 0.38 & 0.00 & 0.00 & 0.25 & 0.00 & 0.04 & 0.38 \\
\hline C2 & -0.03 & 0.18 & 0.70 & -0.05 & 0.11 & 0.53 & -0.05 & 0.00 & 0.35 & -0.03 & 0.18 & 0.70 \\
\hline C3 & -0.05 & 0.16 & 0.90 & 0.00 & 0.37 & 0.90 & -0.05 & 0.00 & 0.45 & -0.03 & 0.21 & 0.90 \\
\hline C4 & -0.25 & 0.21 & 1.00 & -0.13 & 0.35 & 1.00 & -0.25 & 0.00 & 0.50 & 0.00 & 0.49 & 1.00 \\
\hline C5 & -0.03 & 0.29 & 0.90 & -0.05 & 0.21 & 0.90 & -0.05 & 0.00 & 0.45 & -0.05 & 0.08 & 0.68 \\
\hline$\tilde{S}_{j}$ & -0.35 & 0.99 & 4.00 & -0.23 & 1.11 & 3.70 & -0.40 & 0.00 & 2.00 & -0.10 & 1.00 & 3.65 \\
\hline$\tilde{R}_{j}$ & 0.00 & 0.29 & 1.00 & 0.00 & 0.37 & 1.00 & 0.00 & 0.00 & 0.50 & 0.00 & 0.49 & 1.00 \\
\hline
\end{tabular}

The next step is to compute the value of $\tilde{Q}_{i}$ with Eqn 22

$\tilde{Q}_{i}=v\left(\tilde{S}_{i}-\tilde{S}^{*}\right) /\left(S^{\circ c}-S^{* a}\right) \oplus(1-v)\left(\tilde{R}_{i}-\tilde{R}^{*}\right) /\left(R^{\circ c}-R^{* a}\right)$

where $\tilde{S}^{*}=\operatorname{MIN}_{i} \tilde{S}_{i}, S^{\circ c}=\operatorname{MAX} S_{i} S_{i}^{c}, \tilde{R}^{*}=\operatorname{MIN}_{i} \tilde{R}_{i} R^{\circ c}=M A X_{i} R_{i}^{c}$

and $v(v=n+1 / 2 n)$. The computed values of $\tilde{Q}_{i}$ are presented in Table 17.

TABLE 16. THE VALUE OF Q

\begin{tabular}{|c|c|c|c|}
\hline & \multicolumn{3}{|c|}{ Q } \\
\hline A1 & -0.52 & 0.25 & 0.97 \\
\hline A2 & -0.52 & 0.22 & 0.98 \\
\hline A3 & -0.51 & 0.29 & 1 \\
\hline A4 & -0.52 & 0.24 & 0.9 \\
\hline A5 & -0.52 & 0.26 & 1 \\
\hline A6 & -0.5 & 0.31 & 0.97 \\
\hline A7 & -0.52 & 0 & 0.52 \\
\hline A8 & -0.49 & 0.36 & 0.96 \\
\hline
\end{tabular}

The values of $\tilde{Q}_{i} \tilde{S}_{i}$ and $\tilde{R}_{i}$ are then defuzified. The fuzzy numbers are converted into crisp values using the Center of Area method. The values are then ranked with the smaller value of $\tilde{Q}_{i}$ being the best ranked alternative as seen in Table 18.

TABLE 18. THE DEFUZIFIED VALUES AND THE RESPECTIVE RANKS

\begin{tabular}{|c|c|c|c|c|c|c|}
\hline & $Q$ & $S$ & $R$ & $Q$ & $S$ & $R$ \\
\hline $\mathrm{A} 1$ & 0.24 & 1.45 & 0.43 & 4 & 4 & 3 \\
\hline $\mathrm{A} 2$ & 0.23 & 1.39 & 0.43 & 3 & 3 & 2 \\
\hline A3 & 0.26 & 1.58 & 1.58 & 7 & 8 & 8 \\
\hline A4 & 0.2 & 1.29 & 1.29 & 2 & 2 & 6 \\
\hline A5 & 0.25 & 1.55 & 1.55 & 5 & 7 & 7 \\
\hline A6 & 0.26 & 1.53 & 0.46 & 6 & 6 & 4 \\
\hline A7 & 0 & 0.53 & 0.17 & 1 & 1 & 1 \\
\hline A8 & 0.28 & 1.52 & 0.5 & 8 & 5 & 5 \\
\hline
\end{tabular}


The comparative ranks of the three techniques; fuzzy PROMETHEE, fuzzy TOPSIS and fuzzy VIKOR are presented in Table 19.

\begin{tabular}{|c|c|c|c|}
\multicolumn{5}{|c}{ TABLE 18. COMPARATIVE RANKS } \\
\hline & PROMETHEE & TOPSIS & VIKOR \\
\hline A1 & 7 & 4 & 4 \\
\hline A2 & 2 & 3 & 3 \\
\hline A3 & 5 & 7 & 7 \\
\hline A4 & 3 & 2 & 2 \\
\hline A5 & 4 & 5 & 5 \\
\hline A6 & 6 & 6 & 6 \\
\hline A7 & 1 & 1 & 1 \\
\hline A8 & 8 & 8 & 8 \\
\hline
\end{tabular}

From Table 18, the fuzzy TOPSIS and fuzzy VIKOR methods give us the same ranking. This is so because the two methods are distance based measures with similar methodology. Fuzzy PROMETHEE has different ranks from A1 to A5.

\section{SENSITIVITY ANALYSIS}

This section of the paper analyses the cross effect of influenced decisions on the alternatives ratings by the three decision makers. The sensitivity analysis seeks to find out the impact on the ranking if a decision maker is perceived to have been influenced. The alternative ratings by the decision makers in Tables 4 , the ratings of the first three alternatives (A7, A4 and A2) in Table 12 and the top three criteria $(\mathrm{C} 4, \mathrm{C} 3$, and $\mathrm{C} 5)$ in Table 3 are used in the sensitivity analysis for the three scenarios and nine cases as seen in Table19. The alternative ratings of $\mathrm{VH}$ and $\mathrm{EH}$ for these alternatives and criteria are altered to $\mathrm{L}$.

In scenario 1 case 1 , the alternative ratings for decision maker 1 for $\mathrm{A} 7$ are altered for the top three criteria $(\mathrm{c} 4, \mathrm{c} 3, \mathrm{c} 5)$ from $\mathrm{VH}(5.0,7.5,10.0)$ and $\mathrm{EH}(7.5$, $10.0,10.0)$ to $\mathrm{L}(0.0,2.5,5.0)$. All other alternative ratings for the criteria remain the same for decision maker 1 and the other decision makers. In case 2 , criteria (c4, c3, c5) for A7 of decision maker 1 are replaced from $\mathrm{VH}(5.0,7.5$, $10.0)$ and $\mathrm{EH}(7.5,10.0,10.0)$ to $\mathrm{L}(0.0,2.5,5.0)$ while other criteria remain the same for the other alternative ratings for all other decision makers. In case 3, alternative ratings of criteria $(\mathrm{c} 4, \mathrm{c} 3, \mathrm{c5})$ for A2 for decision maker 1 are also replaced from $\mathrm{VH}(5.0,7.5,10.0)$ and $\mathrm{EH}(7.5,10.0,10.0)$ to $\mathrm{L}(0.0,2.5,5.0)$ while other criteria remain the same for the other alternative ratings for all other decision makers.

The same format is applied to scenarios 2 and 3 and for cases 4 to 9 , for the criteria $(\mathrm{c} 4, \mathrm{c} 3, \mathrm{c5})$ and alternatives A7, A4 and A2. Linguistics terms of VH (5.0, $7.5,10.0)$ and $\mathrm{EH}(7.5,10.0,10.0)$ are replaced with $\mathrm{L}(0.0,2.5,5.0)$ on separate basis for decision makers 2 and 3 as shown in Table 10. Steps 5 to 9 are carried out on separate basis for each case under the scenarios and compared with the original ranking to ascertain whether an influenced decision can affect the ranking of the alternatives. 
TABLE 19. COMPARATIVE RANKS

\begin{tabular}{|c|c|}
\hline Case & $\begin{array}{l}\text { (Changes made in Alternatives, At), } \mathrm{A}=\mathrm{A} 1, \mathrm{~A} 2, \ldots, \mathrm{A} 8 \text {, } \\
\mathrm{t}=1,2,3, \ldots, 8\end{array}$ \\
\hline \multirow{3}{*}{$\begin{array}{c}\text { Scenario } 1 \text { (DM } \\
1)\end{array}$} & $\mathrm{A} 7(\mathrm{c} 4, \mathrm{c} 3, \mathrm{c} 5)=(0,2.5,5), \mathrm{A} 1-\mathrm{A} 6, \mathrm{~A} 8$ \\
\hline & $\mathrm{A} 4(\mathrm{c} 4, \mathrm{c} 3, \mathrm{c} 5)=(0,2.5,5), \mathrm{A} 1-\mathrm{A} 3, \mathrm{~A} 5-\mathrm{A} 8$ \\
\hline & $\mathrm{A} 2(\mathrm{c} 4, \mathrm{c} 3, \mathrm{c} 5)=(0,2.5,5), \mathrm{A} 1, \mathrm{~A} 3-\mathrm{A} 8$ \\
\hline \multirow{3}{*}{$\begin{array}{c}\text { Scenario } 2 \text { (DM } \\
\text { 2) }\end{array}$} & $\mathrm{A} 7(\mathrm{c} 4, \mathrm{c} 3, \mathrm{c} 5)=(0,2.5,5), \mathrm{A} 1-\mathrm{A} 6, \mathrm{~A} 8$ \\
\hline & $\mathrm{A} 4(\mathrm{c} 4, \mathrm{c} 3, \mathrm{c} 5)=(0,2.5,5), \mathrm{A} 1-\mathrm{A} 3, \mathrm{~A} 5-\mathrm{A} 8$ \\
\hline & $\mathrm{A} 2(\mathrm{c} 4, \mathrm{c} 3, \mathrm{c} 5)=(0,2.5,5), \mathrm{A} 1, \mathrm{~A} 3-\mathrm{A} 8$ \\
\hline \multirow{3}{*}{$\begin{array}{c}\text { Scenario } 3 \text { (DM } \\
\text { 2) }\end{array}$} & $\mathrm{A} 7(\mathrm{c} 4, \mathrm{c} 3, \mathrm{c} 5)=(0,2.5,5), \mathrm{A} 1-\mathrm{A} 6, \mathrm{~A} 8$ \\
\hline & $\mathrm{A} 4(\mathrm{c} 4, \mathrm{c} 3, \mathrm{c} 5)=(0,2.5,5), \mathrm{A} 1-\mathrm{A} 3, \mathrm{~A} 5-\mathrm{A} 8$ \\
\hline & $\mathrm{A} 2(\mathrm{c} 4, \mathrm{c} 3, \mathrm{c} 5)=(0,2.5,5), \mathrm{A} 1, \mathrm{~A} 3-\mathrm{A} 8$ \\
\hline
\end{tabular}

From Table 11 and Figure 4, the effect of the alterations of the cases for the three scenarios on the rankings of the alternatives are shown with the original ranking. The symbol ' $c 1$ ' stands for case 1, 'c2' for case 2 and so on. A change in the alternative ratings of the three top criteria $(c 4, c 3, c 5)$ for alternatives A7, $\mathrm{A} 4$ and $\mathrm{A} 2$ by a decision maker results in few changes in the alternative rankings of A4 and A2 as seen in Table 20 and Figure 4 below. Alternative 7 remains the top ranked alternative throughout the three scenarios and nine cases as in the original ranking. Alternative 4 also remains the second ranked except for scenario 1(c2), scenario 2(c5) and scenario 3 (c8) where the ranking of the alternative was changed to third. Alternative 2 remained the third ranked except for scenario 1 (c2), scenario 2 (c5) and scenario 3 (c8) which encountered some changes. The rest of the alternatives remained unchanged as seen in Table 11 and Figure 4 below. From the sensitivity analysis, the ranking of the alternatives in the proposed model will not be affected by an influence of an individual decision maker when the same criteria weights are applied.

\begin{tabular}{|c|c|c|c|c|c|c|c|c|c|c|}
\multicolumn{1}{c|}{} \\
\cline { 2 - 12 } & \multicolumn{2}{c|}{ TABLE 20. COMPARATIVE RANKS } \\
\hline & original & $\mathbf{c 1}$ & $\mathbf{c 2}$ & $\mathbf{c 3}$ & $\mathbf{c 4}$ & $\mathbf{c 5}$ & $\mathbf{c 6}$ & $\mathbf{c 7}$ & $\mathbf{c 8}$ & $\mathbf{c 9}$ \\
\cline { 2 - 12 } Alternatives & Rank & Rank & Rank & Rank & Rank & Rank & Rank & Rank & Rank & Rank \\
\hline (A1) & 4 & 4 & 4 & 4 & 4 & 4 & 4 & 4 & 4 & 4 \\
(A2) & 3 & 3 & 2 & 3 & 3 & 2 & 3 & 3 & 2 & 3 \\
(A3) & 7 & 7 & 7 & 7 & 7 & 7 & 7 & 7 & 7 & 7 \\
(A4) & 2 & 2 & 3 & 2 & 2 & 3 & 2 & 2 & 3 & 2 \\
(A5) & 5 & 5 & 5 & 5 & 5 & 5 & 5 & 5 & 5 & 5 \\
(A6) & 6 & 6 & 6 & 6 & 6 & 6 & 6 & 6 & 6 & 6 \\
(A7) & 1 & 1 & 1 & 1 & 1 & 1 & 1 & 1 & 1 & 1 \\
(A8) & 8 & 8 & 8 & 8 & 8 & 8 & 8 & 8 & 8 & 8 \\
\hline
\end{tabular}




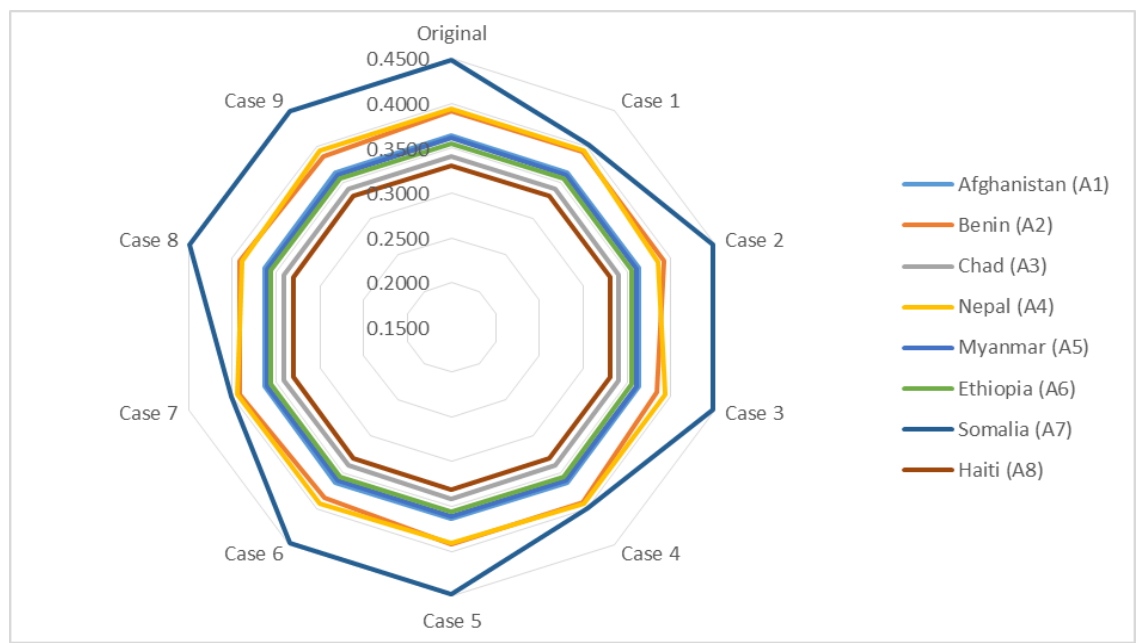

Fig. 4: Plot of result of sensitivity analysis on criteria

\section{Conclusion}

The paper designed a four-stage MCDM framework of Fuzzy PROMETHEE, fuzzy VIKOR, Fuzzy TOPSIS and a novel sensitivity analysis to help evaluate developmental aid programs sponsored by aid-donors around the world. With a numerical example, the framework demonstrates how donor-recipient countries participating in developmental aid program can be evaluated to ascertain progress made and therefore which countries should deserve future funding based on previous performances. The study relied on a set of 5-criteria evaluation format used by OECD countries in evaluating developmental aid programs to model the proposed evaluation technique. With a custom-made rating scale, the framework relies on the experience and the expertise of country development officers and executives in evaluating the performance of participating countries against the set criteria. The strength of the proposed model is seen in how aid-recipient countries can be evaluated by ranking them on their performances thereby ensuring fairness, value for money and sustainability of aid programs. The use of the evaluation process where sensitivity analysis is employed strengthens the framework by ensuring that bias in expert ratings are easily detected to warrant resetting the process again.

\section{ACKNOWLEDGEMENT}

This work was supported by GACR P103/15/06700S, NPU I No. MSMT7778/2014, CEBIA-Tech No. CZ.1.05/2.1.00/03.0089. It was also supported by Internal Grant Agency of TBU under the project Nos. IGA/FAI/2015/054, IGA/FaME/2016/019 and IGA/FaME/2015/023. 


\section{REFERENCES}

[1] OECD (2014) International Development Statistics. OECD Press

[2] K. Kharas, "Measuring Aid Effectiveness Effectively: A Quality of Official Development Assistance Index," Brookings Institution Press, 2011, Available at: http://www.brookings.edu/research/opinions/2011/07/26-aideffectiveness-kharas. Accessed 10/12/2014.

[3] S. Howes "A Framework for Understanding Aid Effectiveness Determinants, Strategies and Tradeoffs," Asia \& the Pacific Policy Studies, 1(1), 2014, pp.58-72.

[4] C. J. Dalgaard, and H. Hansen, "Evaluating Aid Effectiveness in the Aggregate: A critical assessment of the evidence," University Library of Munich, Germany, 2010.

[5] A. Deaton, "Instruments, randomization, and learning about development," Journal of economic literature, 2010, pp. 424-455.

[6] C. Arndt, S. Jones and F. Tarp, “Aid, growth, and development: have we come full circle?" Journal of Globalization and Development, 1(2), 2010.

[7] H. Doucouliagos and M. Paldam, "The aid effectiveness literature: The sad results of 40 years of research," Journal of Economic Surveys, 23(3), 2009, pp. 433-461.

[8] C. Minoiu and S.G Reddy, "Development aid and economic growth: A positive long-run relation," The Quarterly Review of Economics and Finance, 50(1), 2010, pp. 27-39.

[9] K. M. Morrison, "As the World Bank turns: Determinants of IDA lending in the Cold War and after," Business and Politics, 13(2), 2011.

[10] S. Claessens, D. Cassimon and B. Van Campenhout, "Evidence on changes in aid allocation criteria," The World Bank Economic Review, 23(2), 2009, pp. 185-208.

[11] A. Zadeh, "Fuzzy sets." Information and control 8, no. 3, 1965, pp. 338 353.

[12] E. Afful-Dadzie, S. Nabareseh, A. Afful-Dadzie and Z. K. Oplatková, “A fuzzy TOPSIS framework for selecting fragile states for support facility," Quality \& Quantity, 2014, pp. 1-21. doi: 10.1007/s11135-014-0062-3

[13] R. A. Krohling and V. C. Campanharo, "Fuzzy TOPSIS for group decision making: A case study for accidents with oil spill in the sea," Expert Systems with Applications, 38(4), 2011, pp. 4190-4197.

[14] J. P. Vincke and Ph Brans, "A preference ranking organization method. The PROMETHEE method for MCDM," Management Science 31(6), 1985, pp. 647-656.

[15] C. Ying-Hsiu, W. Tien-Chin and W. Chao-Yen, "Strategic decisions using the fuzzy PROMETHEE for IS outsourcing," Expert Systems with Applications 38(10), 2011, pp. 13216-13222. 
[16] T. M. Amaral, and P. C C. Ana, "Improving decision-making and management of hospital resources: An application of the PROMETHEE II method in an Emergency Department," Operations Research for Health Care 3(1), 2014, pp. 1-6.

[17] B. Elevli, "Logistics freight center locations decision by using FuzzyPROMETHEE." Transport 29(4), 2014, pp. 412-418.

[18] P. Yi, G. Kou, and J. Li, "A fuzzy promethee approach for mining customer reviews in chinese." Arabian Journal for Science and Engineering, 39(6), 2014, pp. 5245-5252.

[19] R. M. Shadman, S. Rahimi and M. J. Beglou, "PROMETHEE II and fuzzy AHP: an enhanced GIS-based landslide susceptibility mapping," Natural Hazards, 73(1), 2014, pp. 77-95.

[20] T. Xiaojuan, X. Liu and L. Wang, "An improved PROMETHEE II method based on Axiomatic Fuzzy Sets." Neural Computing and Applications, 25(78), 2014, pp. 1675-1683.

[21] C. Ting-Yu, "A PROMETHEE-based outranking method for multiple criteria decision analysis with interval type-2 fuzzy sets." Soft Computing, 18(5), 2014, pp. 923-940.

[22] H. Sonia and N. Halouani, "Hesitant-fuzzy-promethee method." In Modeling, Simulation and Applied Optimization (ICMSAO), 2013 5th International Conference on, pp. 1-6. IEEE, 2013.

[23] L. Wei-xiang and B. Li, "An extension of the Promethee II method based on generalized fuzzy numbers." Expert Systems with Applications, 37(7), 2010, pp. 5314-5319.

[24] A. Afful-Dadzie, E. Afful-Dadzie, S. Nabareseh and Z. K. Oplatková, "Tracking progress of African Peer Review Mechanism (APRM) using fuzzy comprehensive evaluation method," Kybernetes, 43(8), 2014, pp. 1193-1208

[25] KP, Yoon \& CL. Hwang, "Multiple attribute decision making: an introduction", Sage Publications, 104, 1995.

[26] E., Afful-Dadzie, S., Nabareseh, Z. K., Oplatková, P. \& Klímek, "Model for Assessing Quality of Online Health Information: A Fuzzy VIKOR Based", Method. Journal of Multi-Criteria Decision Analysis, 2015 